\title{
Hypolipidemic, antioxidant and anti- atherosclerogenic effect of aqueous extract leaves of Cassia. occidentalis Linn (Caesalpiniaceae) in diet-induced hypercholesterolemic rats
}

\author{
Ntchapda Fidèle ${ }^{1 *}$, Barama Joseph¹, Talla Emmanuel ${ }^{2}$ and Dimo Théophile ${ }^{3}$
}

\begin{abstract}
Background: Hyperlipidemia and oxidative stress are major risk factors for atherosclerosis, and all three are among the most important risk factors for cardiovascular diseases. Cassia occidentalis aqueous extract has been used in African traditional medicine for the treatment of hypertension and associated cardiovascular diseases. This study was undertaken to evaluate the hypolipidemic and anti-atherosclerotic properties of the aqueous extract of the leaves of $\mathrm{C}$. occidentalis in rats with hypercholesterolemia (HC).

Sixty Normocholesterolemic (NC) male rats were divided into six groups $(n=10)$ and fed a high-cholesterol $(\mathrm{HC})$ diet for 30 days (5 groups), or normal rat chow (normal control group). The plant extract was administered to animals at the increasing dose of 240, 320 and $400 \mathrm{mg} / \mathrm{kg}$. After 4 weeks of treatment 5 rats out of 10 were sacrificed, blood samples, aorta, liver, and fresh faecal were collected and processed for biochemical tests. The experiments were conducted under the same conditions with a group of rat treated with Atorvastatin ( $1 \mathrm{mg} / \mathrm{kg})$, used positive control. The effects of $C$. occidentalis on weight gain, water and food consumptions, levels of serum lipids and lipoprotein lipid oxidation and stress markers in blood and liver were also examined.
\end{abstract}

Results: A significant body weight gain was observed in general in all the group of animals without any treatment after 4 weeks. During the treatment period, the $C$. occidentalis extract induced a significant increase $(P<0.01)$ in water consumption and food intakes. After 4 weeks of treatment with hypercholesterolemia, the body temperature and organ weights including the liver, kidney, heart and the testis did not present any significant change. The administration of $C$. occidentalis extract significantly $(p<0.05)$ prevented the elevation in TC, LDL-C, VLDL-C, hepatic and aortic TG and TC. The atherogenic, triglycerides, and lipid peroxidation (TBARS) index were also decreased in the rats treated with the plant extract. C. occidentalis favoured the performance of faecal cholesterol. It also significantly inhibited the changes and the formation of aortic atherosclerotic plaques.

Conclusion: This study provides evidence of hypolipidemic and antiatherosclerotic effects of $C$. occidentalis extract. C. occidenntalis aqueous extract reduced bad cholesterols, triglycerides and increasing good cholesterols in rats subjected to a feeding regime enriched with cholesterol. The results support the traditional use of the extract of this plant in the treatment of hypertension and diabetes.

Keywords: Cassia occidentalis, Hypolipidemic, Anti-atherosclerotic, Lipid peroxidation TBARs

\footnotetext{
*Correspondence: ntchapda71@yahoo.fr

'Department of Biological Sciences, Faculty of Science, University of

Ngaoundéré, P.O. Box 454, Ngaoundéré, Cameroon

Full list of author information is available at the end of the article
} 


\section{Background}

Hyperlipidemia and oxidative stress are major risk factors for atherosclerosis, and all three are among the most important risk factors for cardiovascular diseases and conditions $[1,2]$. The cardiovascular diseases constitute one of the absolutely largest public health problem in the world. According to the World Health Organization statistics [3], they are responsible of more than 17 million deaths annually. The cardiovascular diseases are associated to several cardio-metabolic risk factors such as hypercholesterolemia, diabetes, high blood pressure, obesity and sedentarity [4]. Dyslipidemia is a very frequent metabolic disorder which is characterized by an increase of the rates of triglycerides (TG), total cholesterol (CT), cholesterol of the low density lipoprotein (LDL-c) and a reduction of the cholesterol high density lipoprotein (HDL-c) [4]. A huge body of population based and experimental evidence shows that high levels of plasma low density lipoprotein (LDL-c) cholesterol and total cholesterol considerably increase the risk for developing atherosclerosis and associated arterial hypertension $[5,6]$. Other changes in lipid parameters associated with atherosclerosis include decreases in high density lipoprotein (HDL-c) cholesterol and increases in triglycerides. It is well documented that hypercholesterolemia contributes to the development of the atherosclerosis, with hypertension and the renal failure [7]. The assumption of responsibility of the hypercholesterolemia in reduction of mortality as well as which has occurred of the events cardio/neurovasculaires, this via the reduction in the blood concentration of cholesterol related to the lipoproteins of low density (LDL-c). The low-density lipoprotein cholesterol (LDL-c) reduction is correlated with the magnitude of cardiovascular risks reduction.

For many decades medicinal plants have been used to prevent or treat various diseases. They are used throughout the world, for their hypoglycemia, hypolipidemia or antioxidant activities [8, 9]. Cassia occidentalis Linn. (Caesalpiniaceae) is a diffuse shrub (usually annual), with loosely spreading branches (60-150 cm long), and can grow up to an altitude of $1500 \mathrm{~m}$ [10]. Different parts of this plant have been reported to possess antiinflammatory, antihepatotoxic [11], antibacterial [12], antiplasmodial [13] and antidiabetic [14] activities. They possess purgative, tonic, febrifugal, expectorant, and diuretic properties. The plant is also used to cure sore eyes, hematuria, rheumatism, typhoid, asthma, hemoglobin disorders and it is also reported to cure leprosy. A wide range of chemical constituents isolated from C. occidentalis include sennoside, anthraquinone glycoside [15], fatty oils, flavonoid glycosides, galactomannan, polysaccharides, and tannins [16]. Although leaves aqueous extract of $C$. occidentalis were reported to possess diuretic effects [17], no data on the effect of this medicinal plant on cardiovascular diseases and conditions are available. The present study therefore aimed at evaluating the anti-dyslipidemic, antioxidant, and anti-atherogenic effects of $C$. occidentalis leaf aqueous extracts and potential mechanisms driving its putative protective and therapeutic effects.

\section{Methods \\ Plant material}

Fresh leaves of C. occidentalis used in this study were harvested in Mora $60 \mathrm{Km}$ from Maroua, the largest city in the Far North Region, Cameroon in July 2013. They were identified by experts of the National Herbarium of Cameroon and a sample was deposited (specimen $\mathrm{N}^{0}$ 21057/SFR/CAM). Leaves of C. occidentalis were extracted as described previously [17].

\section{Preparation of leave aqueous extract}

Fresh leaves of $C$. occidentalis were soaked in distilled water (1000 $\mathrm{g}$ for $1 \mathrm{~L}$ at room temperature) for $12 \mathrm{~h}$. The macerate was filtered through Whatman filter paper $\mathrm{N}^{\mathrm{o}} 3$, and the filtrate concentrated in a rotary evaporator at $40{ }^{\circ} \mathrm{C}$ for $24 \mathrm{~h}$. This process was repeated until an oily paste extract was obtained (130 g), which represented the concentrated crude extract of $C$. occidentalis leaves. The extract was stored at $-20{ }^{\circ} \mathrm{C}$ until use. The solution of $C$. occidentalis extract with the highest concentration tested was prepared by dissolving $800 \mathrm{mg}$ of the concentrated crude extract obtained previously in $10 \mathrm{ml}$ of distilled water (80 $\mathrm{mg} / \mathrm{mL}$ concentration). The other solutions used in the study were 4:5, 3:5, 2:5, and 1:5 dilutions of this solution in distilled water. Solutions were given per os in a volume of $5 \mathrm{ml} / \mathrm{kg}$ body weight, thus, the increasing doses of aqueous extract of $\mathrm{C}$. occidentalis tested were $80,160,240,320$, and $400 \mathrm{mg} / \mathrm{kg}$.

\section{Preliminary qualitative phytochemical analysis}

In order to identify the chemical structure of the compounds responsible for the antioxidant and antiatherosclerogenic activity, preliminary tests of the phytochemical study were conducted following the procedures described by Trease and Evans [18]. Briefly, Essential oils from the aqueous extract of C. occidentalis were extracted with hexane. These extracts were then stitched onto plates of thin layer chromatography on silica, the first disclosure was obtained by ultraviolet radiation (254 $\mathrm{nm}$ and $365 \mathrm{~nm}$ ) and then with vanillin. Analytical tests for the identification of different families of metabolites in crude extracts of the leaves were performed at the national Institute of Medicinal Plants for Medicinal research (IMPM, Cameroon). 


\section{Animals}

Sixty normo-cholesterolemic (NC) male Wistar rats (178.35 $\pm 1.46 \mathrm{~g})$ were purchased from Yaounde (Cameroon) Pasteur Institute and acclimated to the Laboratory of Medicinal Plants, Health and Galenic Formulation of the Department of Biological Sciences, University of Ngaoundere (Cameroon). Animals were housed under controlled room temperature $\left(24 \pm 2{ }^{\circ} \mathrm{C}\right)$ and had ad libitum access to food [National Veterinary Laboratory (LANAVET), Garoua, Cameroon] and tap water. Animals were monitored for signs of general toxicity, under the supervision of a veterinarian. The number of animal per group approved in the experiments by the institutional committee of ethics was five. All experimental procedures were approved by the institutional Ethical committee of Department of Biological Science of the university of Ngaoundéré (ECDBSUN 15/01/ 2015/UN/FS/DSB).

\section{Experimental procedures}

Normo-cholesterolemic (NC) (60 rats) were divided into 6 groups of 10 rats. Five groups were fed for 4 weeks with a diet consisting of 50\% Corn Starch, $11.25 \%$ Rice Powder, $01 \%$ vegetable oil, $10 \%$ egg white, $08 \%$ fish meal, 19\% Cellulose, $0.125 \%$ mineral complex, $0.125 \%$ vitamin Complex and $0.50 \%$ Salt $[19,20]$. For induction of hypercholesterolemia $(\mathrm{HC}), 1 \%$ of cholesterol was added in the feed of rats. The nutrient contents of the $\mathrm{NC}(\mathrm{g} /$ $100 \mathrm{~g}$ food) diet were: total lipid (19.70 \pm 0.28$)$; protein $(32.95 \pm 2.4)$; ash $(0.02 \pm 0.005)$; fiber $(12.33 \pm 1.50)$; carbohydrates $(35 \pm 2.3)$ [21]. The plant extract was administered to animals at the increasing dose of 240, 320 and $400 \mathrm{mg} / \mathrm{kg}$. After 4 weeks of treatment 5 rats out of 10 were sacrificed, blood samples, aorta, liver, and fresh faecal were collected and processed for biochemical tests. The remaining 5 rats were sacrificed 4 weeks after the end treatment and blood were collected again for biochemical analysis. Results were later compared to first group to confirm the anti-atherogenic properties of the leaves extract. Blood collected in heparinized tubes, were centrifuged at $3000 \mathrm{rev} / \mathrm{min}$ for $10 \mathrm{~min}$; the supernatant (plasma) was used for the enzymatic determination of total cholesterol, HDL-c and triglycerides and malondialdehyde. Blood pellet was used in the preparation of hemolysates while the portion of the liver collected was used to prepare liver homogenates for the dosage of catalase, hydroperoxides and proteins. The experiments were conducted under the same conditions with Atorvastatin (1 mg/kg), as pharmacological reference substance.

\section{Body temperature monitoring}

Body temperature of treated rats was monitored daily $5 \mathrm{~h}$ after treatment using a rat rectal thermometer. It was inserted at a distance of approximately $2 \mathrm{~mm}$ in the anus.

\section{Statistical analysis}

Data obtained from the different experimental groups were compared by one-way ANOVA followed by LSD test for post hoc analysis, using Origin software (Origin Lab, Northampton, MA, USA). Test groups were compared to normal, disease, and positive control groups. Differences with $P<0.05$ were considered significant. Data are presented as mean \pm SEM.

\section{Results \\ Body weight}

During the 4 weeks period of induction, the body weight of animals in the Normocholesterolemic fed with cholesterolfree diet, significantly increased $(P<0.05)$ from $3.22 \%$ in week one to $17.12 \%$ at week 4 . Animals fed with a diet rich in cholesterol, have seen their body weights increased significantly $(P<0.05)$ to $5.11 \%$ in week 1 to $49.11 \%$ at week 4 (Fig. 1). During the four weeks of treatment extract-treated animals showed a dose-dependent loss of body weight. Animals treated daily with a dose of $240 \mathrm{mg} / \mathrm{kg}$ of the extract experienced a decreased in the relative body weight of $2.67 \%$ and $8.39 \%$ respectively in week 1 and week 4 . with the slope $y=-3.14 x+264.6, r^{2}=0.97$. At a daily dose of $320 \mathrm{mg} / \mathrm{kg} y=-5.67 x+264.2, r^{2}=0.95$, and animals that received the extract at a dose $400 \mathrm{mg} / \mathrm{kg}$, have seen their body weight decreased from $268.33 \pm 0.82 \mathrm{~g} /$ rat to $247.66 \pm$ $3.68 \mathrm{~g} /$ rat in week 1 and from $247.66 \pm 3.68 \mathrm{~g} /$ rat to 199.77 $\pm 3.87 \mathrm{~g} /$ rat in week 4 , leading to a decrease of $8.34 \%$ and $34.31 \%$ respectively with the slope $y=-9.83 x+271.1, r^{2}=$ 0.98 (Fig. 1). The increase in body weight observed in animals receiving Atorvastatin was also significant $(P<0.05)$ (Fig. 1). A significant body weight gain was observed in general in all the group of animals without any plant extract treatment 4 weeks after (Fig. 1).

\section{Water consumption and food intake}

Average daily water and food intake are shown in Tables 1 and 2. During the treatment, the $C$. occidentalis extract caused a significant increase $(P<0.01)$ in water consumption and food intake. At a dose of $400 \mathrm{mg} / \mathrm{kg}$, the increase of drinking water was $29,89 \%$ and $49,88 \%$ respectively in the first week and fourth week. Four weeks after treatment, water consumption decreased in animals previously treated with aqueous extract. At the dose of $400 \mathrm{mg} / \mathrm{kg}$, water consumption decreased by $60.61 \%$ and $180.77 \%$ respectively in week 1 and week 4, when compared to the water consumption during the treatment at the same dose (Table 1). On the other hand, food intake also increased comparably in all groups. $\mathrm{HC}+$ distilled water group showed an increase of $44.66 \pm 1.12 \%$ and $57.87 \pm 1.23 \%$ respectively in the 1st week and in the fourth week in food consumption during treatment $\left(y=1.25 x+17.4, r^{2}=0.99\right)$ (Table 2). During the 4 weeks of hypercholesterolemia treatment, food consumption significantly decreased 


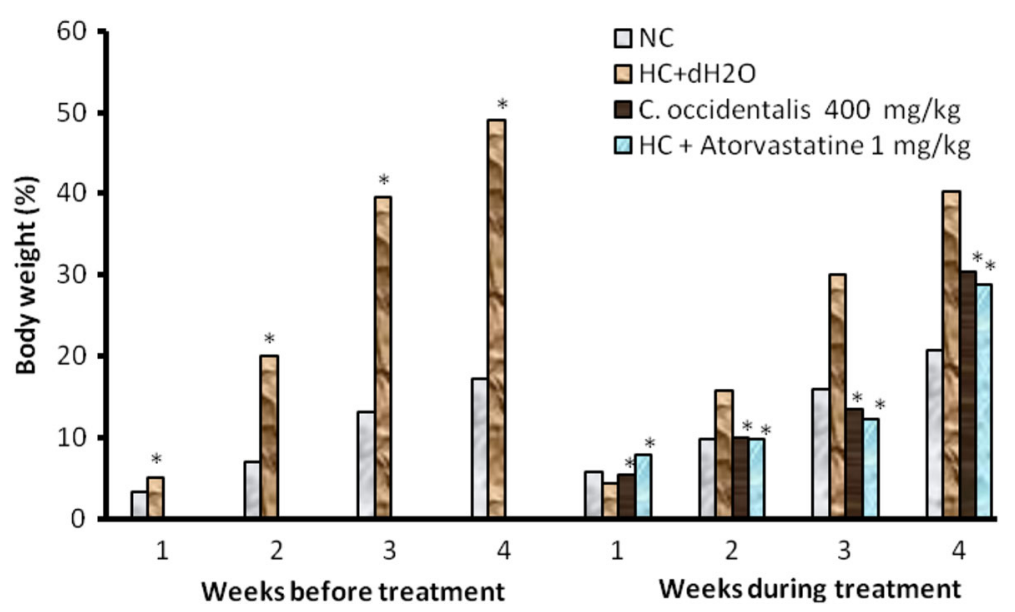

Fig. 1 variation of the body weight of the rats per week. Values are represented as mean \pm standard error of mean, $n=5$. $d H 2 O$ : distilled water. HC: Hypercholesterolemic rats; NC: Normocholesterolemic rats

$(P<0.05)$ in treated animals compared to $\mathrm{HC}+$ distilled water. At the dose of $400 \mathrm{mg} / \mathrm{kg}$, there was a decrease in food intake of $39.55 \pm 1.33 \%$ in the first week and $23.68 \pm$ $1.45 \%$ in week 4 compared to $\mathrm{HC}+\mathrm{H}_{2} \mathrm{O}(y=2.24 x+16.76$, $\left.r^{2}=0.97\right)$. At a dose of $240 \mathrm{mg} / \mathrm{kg}\left(y=3.45 x+13.56, r^{2}=\right.$ $0.99), 320 \mathrm{mg} / \mathrm{kg}\left(y=2.32 x+18.83, r^{2}=0.99\right)$, and Atorvastatin $\left.\left(y=1.69 x+19.14, r^{2}=0.93\right)\right]$ (Table 2).

\section{Organ weight}

After 4 weeks of treatment of hypercholesterolemia, the Organ weight including the liver, kidney, heart and the testis of animals received extract at doses $(240,320$ and $400 \mathrm{mg} / \mathrm{kg}$ ) compared with the group hypercholesterolemic untreated and groups normocholesterolemic did not present any significant change $(<0.05)$ (Table 3$)$.

\section{Body temperature}

No significant change was observed in the body temperature in treated animals compared to Hypercholesterolemic + distilled water and atorvastatin; or after inter-group comparisons, during the treatment period (Table 4) and 4 weeks after (data not shown). Effects of aqueous extract leaves of $C$. occidentalis on body temperature measured daily 5 -h after treatment are presented in Table 4 .

\section{Effect of aqueous extract of C. occidentalis on blood lipid parameters \\ During treatment}

Rat treated with extract showed a significant reduction and dose-dependent of TC level. TC decreased from $156.09 \pm 0.92 \mathrm{mg} / \mathrm{dl}$ to $135.51 \pm 0.51 \mathrm{mg} / \mathrm{dl}$, at a dose of $240 \mathrm{mg} / \mathrm{kg}, 116.63 \pm 0.54 \mathrm{mg} / \mathrm{dl}$ at a dose of $320 \mathrm{mg} / \mathrm{kg}$, and $106.07 \pm 0.69 \mathrm{mg} / \mathrm{dl}$ at a dose of $400 \mathrm{mg} / \mathrm{kg}$, leading to a decrease of $13.18 \%, 25.28 \%$ and $32.05 \%$ respectively. TC also decreased in the group which received a treatment compared to the normocholesterolemic (Table 5).

TG decreased from from $141.01 \pm 0.63 \mathrm{mg} / \mathrm{dl}$ to $101.62 \pm 0.98 \mathrm{mg} / \mathrm{dl}$ leading to a decrease of $27.93 \%, 32.58 \%$ and $39.62 \%$ respectively at a doses 240,320 and $400 \mathrm{mg} / \mathrm{kg}$ compared to the normocholesterolemic (Table 5).

Table 1 Variation of water consumption

\begin{tabular}{|c|c|c|c|c|c|c|}
\hline & Drugs & $\begin{array}{l}\text { Doses } \\
\mathrm{mg} / \mathrm{kg}\end{array}$ & $\begin{array}{l}\text { 1st week } \\
\text { (ml/rat/week) }\end{array}$ & $\begin{array}{l}\text { 2nd week } \\
\text { (ml/rat/week) }\end{array}$ & $\begin{array}{l}\text { 3rd week } \\
\text { (ml/rat/week) }\end{array}$ & $\begin{array}{l}\text { 4th week } \\
\text { (ml/rat/week) }\end{array}$ \\
\hline & HC + Distilled water & 0 & $116.12 \pm 1.21$ & $137.12 \pm 1.12$ & $142.10 \pm 1.22$ & $146.21 \pm 1.32$ \\
\hline \multirow[t]{4}{*}{ During treatment } & $\mathrm{HC}+$ Extract & 240 & $179.04 \pm 1.23^{* a}$ & $158.32 \pm 1.16^{* a}$ & $160.24 \pm 1.14^{* a}$ & $179.31 \pm 1.22^{* a}$ \\
\hline & & 320 & $139.43 \pm 1.22^{* * a}$ & $200.31 \pm 1.32^{* * a}$ & $215.12 \pm 1.32^{* * a}$ & $236.83 \pm 1.11^{* * a}$ \\
\hline & & 400 & $178.43 \pm 2.33^{* * a}$ & $239.25 \pm 1.67^{* * a}$ & $265.27 \pm 2.37^{* *^{a}}$ & $289.66 \pm 1.23^{* * a}$ \\
\hline & $\mathrm{HC}+$ Atorvastatin & 1 & $145.95 \pm 1.12$ & $164.75 \pm 1.13$ & $174.15 \pm 1.13$ & $166.64 \pm 1.12$ \\
\hline \multirow[t]{4}{*}{ After treatment } & $\mathrm{HC}+$ Extract & 240 & $86.33 \pm 1.17^{* * \mathrm{~b}}$ & $88.44 \pm 1.17^{* * b}$ & $89.22 \pm 1.17^{* * b}$ & $89.10 \pm .1 .20^{* * \mathrm{~b}}$ \\
\hline & & 320 & $95.32 \pm 1.66^{* * b}$ & $86.22 \pm 1.16^{* * b}$ & $97.12 \pm 1.77^{* * b}$ & $98.44 \pm 1.25^{* * b}$ \\
\hline & & 400 & $103.93 \pm 1.11^{* * \mathrm{~b}}$ & $99.77 \pm 1.11^{* * b}$ & $100.93 \pm 1.01^{* * \mathrm{~b}}$ & $101.65 \pm 0.83^{* * b}$ \\
\hline & $\mathrm{HC}+$ Atorvastatin & 1 & $141.85 \pm 3.72$ & $162.75 \pm 2.76$ & $160.75 \pm 3.78$ & $166.69 \pm 1.03$ \\
\hline
\end{tabular}

Values are means \pm S.E.M., $n=5,{ }^{*} P<0.05,{ }^{* *} P<0.01$ significant difference compared to $\mathrm{HC}+$ Distilled water. HC Hypercholesterolemic rat; ${ }^{\text {a }}$ significant difference compared to HC+ Distilled water; ${ }^{b}$ significant difference compared to animals previously treated with aqueous extract during the treatment at the same dose 
Table 2 Variation of the food intake during treatment

\begin{tabular}{|c|c|c|c|c|c|c|}
\hline & Drugs & $\begin{array}{l}\text { Doses } \\
\mathrm{mg} / \mathrm{kg}\end{array}$ & $\begin{array}{l}\text { 1st week } \\
(\% / \text { week })\end{array}$ & $\begin{array}{l}\text { 2nd week } \\
\text { (\%/week) }\end{array}$ & $\begin{array}{l}\text { 3rd week } \\
(\% / \text { week })\end{array}$ & 4th week (\%/week) \\
\hline & $\mathrm{HC}+$ Distilled water & 0 & $44.66 \pm 1.12 \%$ & $54.12 \pm 1.10 \%$ & $55.11 \pm 1.22 \%$ & $57.87 \pm 1.23 \%$ \\
\hline \multirow[t]{4}{*}{ During treatment } & $\mathrm{HC}+$ Extract & 240 & $56.80 \pm 1.12 \%$ & $54.47 \pm 1.14 \%$ & $50.23 \pm 1.24 \%^{* a}$ & $47.47 \pm 1.32 \% * * a$ \\
\hline & & 320 & $54.23 \pm 1.45 \%$ & $52.39 \pm 1.09 \% \%^{* a}$ & $50.22 \pm 1.19 \% \%^{* a}$ & $45.39 \pm 1.23 \% * * a$ \\
\hline & & 400 & $39.55 \pm 1.33 \%^{* a}$ & $35.54 \pm 1.32 \%^{* a}$ & $28.34 \pm 1.12 \%^{* * a}$ & $23.68 \pm 1.45 \% * * a$ \\
\hline & $\mathrm{HC}+$ Atorvastatin & 1 & $36.17 \pm 1.32 \% \%^{* * a}$ & $37.16 \pm 1.06 \% * * a$ & $39.37 \pm 1.32 \% * \%^{* a}$ & $43.41 \pm 1.13 \% \%^{* a}$ \\
\hline \multirow[t]{4}{*}{ After treatment } & $\mathrm{HC}+$ Extract & 240 & $53.13 \pm 1.56 \%$ & $56.32 \pm 1.21 \% * b$ & $58.87 \pm 1.22 \% * b$ & $62.23 \pm 1.12 \% * * b$ \\
\hline & & 320 & $56.16 \pm 1.32 \% \%^{* b}$ & $55.33 \pm 1.41 \% * b$ & $60.77 \pm 1.42 \% * b$ & $62.44 \pm 1.54 \% * * b$ \\
\hline & & 400 & $47.33 \pm 1.22 \% \%^{* b}$ & $49.33 \pm 1.25 \% *$ *b & $52.22 \pm 1.32 \% *$ *b & $59.80 \pm 1.11 \% *$ *b \\
\hline & $\mathrm{HC}+$ Atorvastatin & 1 & $39.21 \pm 1.14 \% *$ b & $41.89 \pm 1.31 \% * b$ & $45.82 \pm 1.34 \% * b$ & $49.15 \pm 1.22 \% * * b$ \\
\hline
\end{tabular}

Values are means \pm S.E.M., $n=5,{ }^{*} P<0.05,{ }^{* *} P<0.01, H C$ Hypercholesterolemic rat; ${ }^{a}$ significant difference compared to HC+ Distilled water; ${ }^{b}$ significant difference compared to animals previously treated with aqueous extract during the treatment at the same dose

Table 4 also shows HDL-c rate during treatment. Rats treated with Atorvastatin showed a significant decreased of HDL-c level compared to the normocholesterolemic, leading to a decrease of $3.33 \%$. Rat treated with extract showed a significant reduction and dose-dependent of HDL-c levels, compared to the normocholesterolemic, leading to a decrease of $13.33 \%, 6.66 \%$ and an increase of $13.33 \%$ respectively at the doses of 240,320 and $400 \mathrm{mg} /$ $\mathrm{kg}$ compared to the normocholesterolemic (Table 5).

LDL-c rate decrease from $109.28 \pm 0.49 \mathrm{mg} / \mathrm{dL}$ with the normocholesterolemic to $53.02 \pm 0.83 \mathrm{mg} / \mathrm{dL}$ for the rats treated with Atorvastatin, and to $81.53 \pm$ $0.5 \mathrm{mg} / \mathrm{dL}, 53.02 \pm 0.83 \mathrm{mg} / \mathrm{dL}, 36.17 \pm 0.34 \mathrm{mg} / \mathrm{dL}$ for the rats treated with extract at the doses of 240,320 and $400 \mathrm{mg} / \mathrm{kg}$ respectively compared to the normocholesterolemic (Table 5).

VLDL-c levels decrease from $28.21 \pm 0.73$ with the normocholesterolemic to $20.33 \pm 0.79,19.02 \pm 0.66$ and $16.65 \pm 0.38$, with the rats treated with extract with the doses of 240,320 and $400 \mathrm{mg} / \mathrm{kg}$ respectively compared to the normocholesterolemic. Leading to a decrease of $27.93 \%, 32.57 \%$ and of $40.97 \%$ respectively at the doses of 240,320 and $400 \mathrm{mg} / \mathrm{kg}$ compared to the normocholesterolemic (Table 5). Treatment with Atorvastatin, showed a decrease of $38.78 \%$.

\section{Ratio of LDL/HDL-C and TC/HDL-C}

In normocholesterolemic, the TC/HDL-c had a nonsignificant increase $(P>0.05)$, whereas LDL/HDL-c also showed no significant differences $(P>0.05)$. Hypercholesterolemic rat treated with Atorvastatin showed a 365.87\% reduction in LDL/HDL-c against $156.53 \%$ in TC/HDL-c levels. Rats treated with the extract at the dose of $400 \mathrm{mg} /$ $\mathrm{kg}$ showed a reduction of LDL/HDL-c ratio of $511.45 \%$ when compared to the Hypercholesterolemic + distilled water rats. This reduction was also observed in the $\mathrm{TC} /$ HDL-c and the value decreased from $8.44 \pm 0.82$ in Hypercholesterolemic + distilled water rats to $3.96 \pm 0.15$ in rats treated with the extract at dose of $400 \mathrm{mg} / \mathrm{kg}$, equivalent to a reduction of $113.13 \%$. (Table 5). LDL/HDL-c ratio decreased in a dose-dependent manner when compared with Hypercholesterolemic + distilled water rats.

\section{After treatment}

The interest of this study consisted in checking that after 4 weeks of treatment, the extract would always act.the aim would be to highlight vasodilators which can reconstitute the level of integrity of the endothelium and the production and the diffusion of the oxide nitrite. Four weeks after replacement of Hypercholesterolemic diet with normal rat chow and concomitant end of treatments,

Table 3 Effects of C. occidentalis extract administration for 4 weeks on organ weight

\begin{tabular}{|c|c|c|c|c|c|}
\hline \multirow[t]{2}{*}{ Group } & & \multicolumn{4}{|c|}{ Organ weight } \\
\hline & & Liver & Heart & Kidney & Testis \\
\hline $\mathrm{HC}+\mathrm{dH}_{2} \mathrm{O}$ & & $3.04 \pm 0.71$ & $0.34 \pm 0.07$ & $0.66 \pm 0.35$ & $0.55 \pm 0.12$ \\
\hline \multirow[t]{3}{*}{ C. occidentalis treated } & $240 \mathrm{mg} / \mathrm{kg}$ & $3.04 \pm 0.15$ & $0.33 \pm 0.03$ & $0.64 \pm 0.07$ & $0.53 \pm 0.17$ \\
\hline & $320 \mathrm{mg} / \mathrm{kg}$ & $3.05 \pm 0.91$ & $0.32 \pm 0.07$ & $0.62 \pm 0.53$ & $0.53 \pm 0.14$ \\
\hline & $400 \mathrm{mg} / \mathrm{kg}$ & $3.01 \pm 0.25$ & $0.32 \pm 0.04$ & $0.61 \pm 0.04$ & $0.53 \pm 0.13$ \\
\hline Atorvastatin (1 mg/kg) & & $3.02 \pm 0.18$ & $0.32 \pm 0.07$ & $0.61 \pm 0.06$ & $0.52 \pm 0.16$ \\
\hline NC & & $3.01 \pm 0.26$ & $0.30 \pm 0.10$ & $0.61 \pm 0.25$ & $0.52 \pm 0.18$ \\
\hline
\end{tabular}

Values are represented as mean \pm standard error of mean, $n=5$. No significant change was observed. $d H 2 O$ distilled water, $H C$ Hypercholesterolemic rats, NC Normocholesterolemic rats 
Table 4 Effect of C. occidentalis extract administration for 4 weeks on body temperature

\begin{tabular}{llllll}
\hline $\begin{array}{l}\text { Time } \\
\text { (days) }\end{array}$ & \multicolumn{2}{l}{ Extract of C. occidentalis $(\mathrm{mg} / \mathrm{kg})$} & 300 & \multicolumn{1}{c}{$\begin{array}{c}\text { Atorvastatin } \\
(1 \mathrm{mg} / \mathrm{kg})\end{array}$} \\
\cline { 2 - 5 } & Control & 240 & 320 & $37.13 \pm 0.13$ & $36.13 \pm 0.13$ \\
\hline 1 & $36.11 \pm 0.13$ & $36.12 \pm 0.12$ & $37.14 \pm 0.13$ & $36.11 \pm 0.14$ & $36.12 \pm 0.13$ \\
3 & $36.12 \pm 0.12$ & $36.13 \pm 0.15$ & $35.15 \pm 0.11$ & $36.13 \pm 0.13$ & $37.14 \pm 0.11$ \\
4 & $37.13 \pm 0.12$ & $36.13 \pm 0.11$ & $37.12 \pm 0.12$ & $36.12 \pm 0.12$ & $36.11 \pm 0.13$ \\
5 & $36.12 \pm 0.15$ & $36.14 \pm 0.12$ & $36.14 \pm 0.13$ & $36.12 \pm 0.14$ & $36.12 \pm 0.11$ \\
6 & $36.13 \pm 0.11$ & $36.11 \pm 0.13$ & $36.12 \pm 0.12$ & $36.13 \pm 0.11$ & $36.13 \pm 0.11$ \\
7 & $36.14 \pm 0.13$ & $36.14 \pm 0.13$ & $36.13 \pm 0.13$ & $37.12 \pm 0.13$ & $36.13 \pm 0.13$ \\
30 & $36.11 \pm 0.12$ & $36.12 \pm 0.14$ & $36.14 \pm 0.14$ & $36.12 \pm 0.11$ & $36.12 \pm 0.14$ \\
\hline
\end{tabular}

Values are represented as mean \pm standard error of mean, $n=5$. No significant change was observed dH2O distilled water

physiological levels of blood lipid parameters were still observed in animals treated with either Atorvastatin or a dose of extract (Table 5). Compared to those given normal rat chow (normocholesterolemic rats), animals given a diet enriched in cholesterol 4 weeks and only distilled water (Hypercholesterolemic rats) showed significant $(P<0.05)$ increases in total cholesterol $(124.23 \%)$, in triglycerides (103.01\%), in very low density lipoprotein (VLDL-c) cholesterol (96.03\%), in LDL cholesterol (330.57\%), and a decrease in HDL cholesterol (3.26\%). These alterations were prevented in Hypercholesterolemic rats treated with Atorvastatin, as expected, but also by the three doses of extract in a dose-dependent fashion (Table 5).

\section{Ratio of LDL/HDL-c and TC/HDL-C}

There were a significant changes in LDL/HDL-c and TC/HDL-c ratios in rats, 4 weeks after treatment. LDL/ HDL-c ratio decreased from $5.87 \pm 0.05$ in Hypercholesterolemic + distilled water rats without diet consisting to $0.91 \pm 0.02$ in the rats treated with $C$. occidentalis at the dose of $400 \mathrm{mg} / \mathrm{kg}$ after treatment. The TC/HDL-c also decreased from $8.44 \pm 0.82$ in Hypercholesterolemic + distilled water rats without diet consisting to $2.72 \pm 0.12$ in the rats treated with $C$. occidentalis at the dose of $400 \mathrm{mg} /$ $\mathrm{kg}$ after treatment. (Table 7 ). The of $L D L / H D L-c$ ratios and $T C / H D L-c$ ratios were significantly increased in Hypercholesterolemic rats $(P<0.05)$ compared to normocholesterolemic rats (Table 4). Such alteration in these ratios was prevented in Hypercholesterolemic rats by atorvastatin treatment, but also by treatments with extracts of $C$. occidentalis, in a dose-dependent fashion (Table 5).

\section{Effect of the aqueous extract of $C$ occidentalis on oxidative stress markers in liver homogenates and blood} The effect of the aqueous extract of $C$. occidentalis on various markers of oxidative stress markers in liver homogenates, hemolysates, and plasma was dose-dependent as shown in (Table 6). Catalase activities in liver homogenates and in hemolysates were significantly decreased $(P<0.05)$. The extract also induced a significant decrease in hydroperoxide amount in liver homogenates $(P<$ $0.001)$, and an increase in blood plasma $(P<0.05)$. Plasma and liver malondialdehyde amounts were significantly

Table 5 Effect of aqueous extract of $C$. occidentalis on blood lipid parameters

\begin{tabular}{|c|c|c|c|c|c|c|c|c|}
\hline \multirow{2}{*}{\multicolumn{2}{|c|}{ Experimental groups }} & \multicolumn{7}{|c|}{ Lipid parameters (mg/dL) } \\
\hline & & \multirow{2}{*}{$\begin{array}{l}\mathrm{TC} \\
156.09 \pm 0.92\end{array}$} & \multirow{2}{*}{$\frac{T G}{141.01 \pm 0.63}$} & \multirow{2}{*}{$\frac{V L D L-C}{28.21 \pm 0.73}$} & \multirow{2}{*}{$\frac{H D L-C}{31.05 \pm 0.48^{*}}$} & \multirow{2}{*}{$\frac{L D L-c}{109.28 \pm 0.49}$} & \multirow{2}{*}{$\frac{\mathrm{LDL} / \mathrm{HDL}}{5.87 \pm 0.05}$} & \multirow{2}{*}{$\frac{C T / H D L}{8.44 \pm 0.82}$} \\
\hline $\mathrm{HC}$ rats $+\mathrm{dH}_{2} \mathrm{O}$ & & & & & & & & \\
\hline \multirow{3}{*}{$\begin{array}{l}\mathrm{HC}+4 \text { weeks } \\
\text { treatment }\end{array}$} & $240 \mathrm{mg} / \mathrm{kg}$ & $135.51 \pm 0.51^{*}$ & $101.62 \pm 0.98^{*}$ & $20.33 \pm 0.79^{*}$ & $26.73 \pm 0.47$ & $81.53 \pm 0.5^{*}$ & $3.05 \pm 0.07^{*}$ & $6.25 \pm 0.34^{*}$ \\
\hline & $320 \mathrm{mg} / \mathrm{kg}$ & $116.63 \pm 0,54^{*}$ & $95.06 \pm 0.57^{*}$ & $19.02 \pm 0.66^{*}$ & $28.35 \pm 0.58^{*}$ & $53.02 \pm 0.83^{*}$ & $1.87 \pm 0.06^{*}$ & $4.59 \pm 0.16^{*}$ \\
\hline & 400 mg/kg & $106.07 \pm 0.69^{*}$ & $85.15 \pm 0.64^{*}$ & $16.65 \pm 0.38^{*}$ & $34.77 \pm 0.6^{*}$ & $36.17 \pm 0.34^{*}$ & $0.96 \pm 0.04^{*}$ & $3.96 \pm 0.15^{*}$ \\
\hline \multirow{3}{*}{$\begin{array}{l}\text { HC } 4 \text { weeks after } \\
\text { treatment }\end{array}$} & $240 \mathrm{mg} / \mathrm{kg}$ & $130.12 \pm 0.11^{*}$ & $98.13 \pm 0.30^{*}$ & $18.30 \pm 0.70^{*}$ & $27.12 \pm 0.17$ & $80.31 \pm 0.15^{*}$ & $2.96 \pm 0.02^{*}$ & $4.79 \pm 0.13^{*}$ \\
\hline & $320 \mathrm{mg} / \mathrm{kg}$ & $110.22 \pm 0,34^{*}$ & $89.16 \pm 0.33^{*}$ & $16.12 \pm 0.25^{*}$ & $30.22 \pm 0.32^{*}$ & $48.22 \pm 0.23^{*}$ & $1.59 \pm 0.03^{*}$ & $3.64 \pm 0.11^{*}$ \\
\hline & 400 mg/kg & $99.14 \pm 0.44^{*}$ & $79.17 \pm 0.24^{*}$ & $14.25 \pm 0.31^{*}$ & $36.43 \pm 0.21^{*}$ & $33.27 \pm 0.14^{*}$ & $0.91 \pm 0.02^{*}$ & $2.72 \pm 0.12^{*}$ \\
\hline $\mathrm{HC}+$ Atorvastatin & $1 \mathrm{mg} / \mathrm{kg}$ & $95.23 \pm 0.57^{*}$ & $86.84 \pm 0.84^{*}$ & $17.27 \pm 0.63^{*}$ & $31.05 \pm 0.48^{*}$ & $39.06 \pm 0.97^{*}$ & $1.26 \pm 0.04^{*}$ & $3.29 \pm 0.42^{*}$ \\
\hline \multicolumn{2}{|l|}{ NC rats } & $69.61 \pm 0.92$ & $69.46 \pm 0.58$ & $14.39 \pm 0.57$ & $30.83 \pm 0.39$ & $25.38 \pm 0.66$ & $0.83 \pm 0.07$ & $2.28 \pm 0.07$ \\
\hline
\end{tabular}

Data are represented as mean \pm standard error of mean, $n=5$. One-way ANOVA + LSD test against hypercholesterolemic (HC) rats: ${ }^{*} P<0.05$. $d H_{2} O$ distilled water, $H D L-c$ high density lipoprotein cholesterol, $L D L-c$ low density lipoprotein cholesterol, NC normocholesterolemic, $T$ treatment, $T C$ total cholesterol, $T G$ triglyceride, $V L D L-c$ very low density lipoprotein cholesterol 
Table 6 Effect of the aqueous extract of C. occidentalis on markers of oxidative stress

\begin{tabular}{|c|c|c|c|c|c|c|}
\hline & Experimental groups & $\begin{array}{l}\text { MDA } \\
\text { ( } \mu \mathrm{M} / 100 \mathrm{~g} \\
\text { of tissue) }\end{array}$ & $\begin{array}{l}\mathrm{ROOH} \\
(\mu \mathrm{M} / 100 \mathrm{~g} \\
\text { of tissue) }\end{array}$ & $\begin{array}{l}\text { CAT } \\
\text { (mMH2O2/min } \\
\text { per g of protein) }\end{array}$ & $\begin{array}{l}\text { Protein } \\
\text { (g/100 g } \\
\text { of tissue) }\end{array}$ & $\begin{array}{l}\text { Glutathione } \\
\text { (mmol/L) }\end{array}$ \\
\hline \multirow[t]{2}{*}{ Liver homogenates } & $\mathrm{dH}_{2} \mathrm{O}$ & $10.77 \pm 1.44$ & $1.28 \pm 0.10$ & $0.02 \pm 0.13$ & $54.11 \pm 0.54$ & - \\
\hline & 400 mg/kg extract & $8.89 \pm 1.77^{*}$ & $0.87 \pm 0.15^{* * *}$ & $0.19 \pm 0.17^{*}$ & $29.33 \pm 3.16^{* *}$ & - \\
\hline \multirow[t]{2}{*}{ Blood plasma } & $\mathrm{dH}_{2} \mathrm{O}$ & $19.67 \pm 1.23$ & $0.04 \pm 0.11$ & - & - & $0.44 \pm 0,056$ \\
\hline & 400 mg/kg extract & $7.13 \pm 1.44^{* * *}$ & $0.07 \pm 0.12^{*}$ & - & - & $0.23 \pm 0,033^{* *}$ \\
\hline \multirow[t]{2}{*}{ Blood pellet hemolysates } & $\mathrm{dH}_{2} \mathrm{O}$ & - & - & $0.01 \pm 0.014$ & $43.77 \pm 4.21$ & - \\
\hline & 400 mg/kg extract & - & - & $0.14 \pm 0.14^{* * *}$ & $52.65 \pm 0.43^{*}$ & - \\
\hline
\end{tabular}

CAT catalase, MDA malondialdehyde, $R O O H$ hydroperoxide. Values are mean \pm S.E.M., $n=5$. ANOVA + LSD test vs. negative control: ${ }^{*} P<0.05, * * P<0.01, * * * P<0.001$

decreased $(p<0.05)$. Glutathione concentration in plasma was decreased $(P<0.01)$. Protein amounts were decreased in liver homogenates $(P<0.01)$ and increased in hemolysates $(P<0.05)$. Protein level was decreased in liver homogenates $\left(y=-5.77 x+52.7, r^{2}=0.93\right)$ and increased in hemolysates $\left(y=3.42 x+44.8, r^{2}=0.95\right)$ of Hypercholesterolemic rats treated with the extract. Changes in liver homogenates were significant at higher doses of extract $(P<0.01)$, whereas Catalase level was increased in the liver $\left(y=0.04 x-0.03, r^{2}=0.772\right)$ of Hypercholesterolemic rats treated with the extract (Table 6). Such increase was significant at the highest dose tested $(P<0.05)$. Catalase level was also increased in hemolysates of these animals $\left(y=0.05 x-0.014, r^{2}=0.84\right)$. Malondialdehyde (MDA) level was decreased in the liver $\left(y=-0.77 x+11.19, r^{2}=0.94\right)$ and in blood plasma $\left(y=-3.58 x+33.4, r^{2}=0.96\right)$ of Hypercholesterolemic rats treated with the extract (Table 5$)$. These decreased were significant at higher doses tested $(P<0.05)$. Hydroperoxide $(\mathrm{ROOH})$ level was decreased in the liver at the highest dose tested $\left(y=0.02 x+0.03, r^{2}=0.98, P<0.05\right)$, and in plasma $\left(y=-0.19 x+1.7, r^{2}=0.80\right)$ (Table 6).

\section{Effect of the aqueous extract of $C$ occidentalis on bilirubin, fecal cholesterol and blood urea}

C. occidentalis did not have any change on bilirubin elimination from blood. evertheless, it is necessary to note the lack of significant difference of bilirubin level between rats treated with aqueous extract and the untreated rats (Table 7). During the last 5 days of the treatment, faecal cholesterol was evaluated. Faecal cholesterol of rats treated with extract increased from $1.04 \pm 0.27 \mathrm{mg} / \mathrm{dl}$ to $11.47 \pm 0.75,14.11 \pm 1.63,15.04 \pm$ $1.98 \mathrm{mg} / \mathrm{dl}$ respectively at the doses of 240, 320, $400 \mathrm{mg} / \mathrm{kg}$. Rats treated with atorvastatin showed an increase rate of fecal cholesterol of $1434.61 \%$ compared to the normocholesterolemic. Table 7 shows the blood urea level after treatment. It is deduced from this table that; there is no significant difference in the level of urea present in the blood of rats treated with aqueous extract and the untreated rats (Table 7).

\section{Phytochemical study}

Phytochemical screening performed on crude extracts revealed the presence of several primary and secondary metabolites such as fatty acids, anthraquinones, glycosides, anthracenes, saponins, tannins, and coumarins. Phenolic compounds, triterpenes, volatile oils and sterols, but also flavonoids and alkaloids were also present in the extract. Thin layer chromatography (TLC) showed that the hexane extract and urine of treated rats contained four chemical fractions. These initial observations and findings suggest that the aqueous extract of leaves of $C$. occidentalis contains several chemical compounds with potential biological activities which deserve further investigation.

Table 7 Effect of the aqueous extract of C occidentalis on bilirubin, Faecal cholesterol and blood urea

\begin{tabular}{|c|c|c|c|c|c|}
\hline \multirow[t]{2}{*}{ Experimental groups } & & \multicolumn{4}{|c|}{ Parameters (mg/dL) } \\
\hline & & Bilirubin & Urea & Creatinin & Faecal cholesterol \\
\hline $\mathrm{HC}$ rats $+\mathrm{dH}_{2} \mathrm{O}$ & & $0,87 \pm 0,18$ & $0.47 \pm 0.02$ & $0.41 \pm 0.02$ & $5,58 \pm 1,04$ \\
\hline \multirow[t]{3}{*}{$\mathrm{HC}+4$ weeks treatment } & $240 \mathrm{mg} / \mathrm{kg}$ & $0,90 \pm 0,12$ & $0.31 \pm 0.04^{*}$ & $0.26 \pm 0.04^{*}$ & $11,47 \pm 0,75^{*}$ \\
\hline & $320 \mathrm{mg} / \mathrm{kg}$ & $0,89 \pm 0,14$ & $0.28 \pm 0.05^{*}$ & $0.24 \pm 0.05^{*}$ & $14,11 \pm 1,6^{*}$ \\
\hline & $400 \mathrm{mg} / \mathrm{kg}$ & $0,91 \pm 0,15$ & $0.26 \pm 0.03^{*}$ & $0.22 \pm 0.03^{*}$ & $15,04 \pm 1,98^{*}$ \\
\hline $\mathrm{HC}+$ Atorvastatin & $1 \mathrm{mg} / \mathrm{kg}$ & $0,92 \pm 0,11$ & $0.27 \pm 0.03$ & $0.28 \pm 0.03^{*}$ & $15,96 \pm 1,64^{*}$ \\
\hline NC rats & & $0,94 \pm 0,13$ & $0.35 \pm 0.03$ & $0.25 \pm 0.03$ & $1,04 \pm 0,27$ \\
\hline
\end{tabular}

Data are represented as mean \pm standard error of mean, $n=5$. One-way ANOVA + LSD test against d ${ }_{2} \mathrm{O}:$ distilled rats: ${ }^{*} P<0.05$

HC Hypercholesterolemic rats, NC Normo-cholesterolemic rats 


\section{Discussion}

The aqueous extract of $C$. occidentalis reduced dose dependently and significantly the triglyceride and cholesterol levels in the rats. Ajayi et al. [22], reported that drugs with anticholesteremic properties are also antioxidant. This suggests aqueous extract of $C$. occidentalis may have antioxidant properties. This property could justify the use of the maceration of $C$. occidentalis in traditional medicine to treat hypertension and to reduce the triglyceride and cholesterol levels in blood [23, 24]. In our experiment, animal body weights were significantly increased compared to the controls. This increase could have resulted in the increase in the food and water intakes of the rats. Physiologically, the increase in the appetite could be due to orexine, the stimulative hormone of appetite (Balkan, 2002). Animals fed with a feeding diet rich in cholesterol, have seen their body weights increased significantly, thus developed obesity $[25,26]$. This increase in body weight is due to the increase of fat tissue deposit much more on the level of the hip. We also noted that body weight in rat fed with $\mathrm{HC}+\mathrm{dH}_{2} \mathrm{O}$ is significantly increasing in rat fed with $\mathrm{NC}$ before treatment in Fig. 1. This result means that the well nourished animals can take weight if they are in good health. But what we noted, it is with the difference of $1 \%$ of cholesterol giving in $\mathrm{HC}+\mathrm{dH}_{2} \mathrm{O}$, the Body weight in rat fed with $\mathrm{HC}+\mathrm{dH}_{2} \mathrm{O}$ is significantly increasing than $\mathrm{NC}$ rat. We know that cholesterol induces the hormone synthesis such as cortisol, the aldosteron, the testosteron and the oestrogens which are the sex hormones may be the increasing in cholesterol in the $\mathrm{HC}+\mathrm{dH}_{2} \mathrm{O}$ rats would have contributed to increase the rate of these hormones and induce significantly increasing of body weight in rat fed with $\mathrm{HC}+\mathrm{dH}_{2} \mathrm{O}$.

The treatment with the aqueous extract of $C$. occidentalis, in the rat fed with a diet rich in cholesterol and triglyceride compared with the untreated rat and normal rats, induced a reduction in the contents of VLDL-c. This reduction of cholesterol is found on the level of the TC, the LDL-c and Triglycerides. These results are similar with those of several works completed with other plant extracts, such as the aqueous extract of Dunaliella salina [27] and the ethanolic extract of Crataegus pinnatifida [28], in rats subjected to a feeding regime enriched with lipids. Considering that abnormal lipid profiles constituting the hallmark of $\mathrm{HC}$-induced metabolic syndrome were also prevented in the liver by the extract concomitantly with a marked increase in total cholesterol excreted, we hypothesized that hypolipidemic activity of the extract may be mediated by reducing or inhibiting intestinal cholesterol absorption and increasing reverse cholesterol transport, as observed with agents inducing comparable hypolipidemic effects together with antioxidant effects such as Ezetimibe [29, 30] and bile acid sequestering cholestyramine $[22,31]$. This reduction did not reach the normal rate after 4 weeks of treatment and the 4 weeks without treatment what allow us to say that the treatment during 4 weeks could be insufficient, but we noticed a reduction in the rate of VLDL-c during the 4 weeks without treatment, it could be that the extract of C. occidentalis continued to react and to show the effectiveness of the aqueous extract leaves. This effective action could be explained by the presence of the various chemical families present in the aqueous extract leaves. we limited our research to the treatment in 4 weeks without any time to reassure our self if after the treatment the formation of the atherom could continue and that the endothelium could find its integrity. The interest of this study consisted in checking that after 4 weeks of treatment, the extract would always act.the aim would be to highlight vasodilators which can reconstitute the level of integrity of the endothelium and the production and the diffusion of the oxide nitrite. The ratios $\mathrm{TC} /$ HDL and HDL/LDL are indexes of the coronary risk [32]. The ratios of atherogenicity TC/HDL and HDL/ LDL of dyslipidemic rats treated with the extract of $C$. occidentalis were significantly reduced. These results reflect a lipidic profile antiatherogenic, and let suggest a protective effect of the extract with respect to the hypercholesterolemy induced by the mode enriched out of cholesterol. At the rats hyperlipidemic, saponins, steroid; especially saponins derived from the spirostanol, seem to be responsible for the reduction in total cholesterol. It was noted in all the cases a reduction in LDL-C and sometimes an increase in HDL-c. Saponins would act by formation of a complex with cholesterol or would have a direct effect on the metabolism of cholesterol. Several possible mechanisms of exerciseinduced atheroprotective effects have been proposed such as increased HDL-c, decreased TC, and decreased oxidized LDL-c levels [33]. In the present study, endurance exercise and/or switching from the high fat to the normal diet improved lipid profiles by lowering the atherogenic plasma levels of total and LDL-c. However, the marked change in lipid profile observed concerned the plasma levels of the anti-atherogenic HDL-c. They were significantly increased in the exercise trained groups of rat (independently of the diet used) and not in the sedentary rats which were switched from the high fat to the control diet. Consequently, the atherogenic index was less in the exercise trained than in the rats with modified diet. Concerning plasma triglycerides, studies have also shown that they are strongly correlated with the prevalence and incidence of metabolic syndrome and cardiovascular diseases [34].

Many experimental studies showed the effectiveness of the medicinal plants or their extracts in the improvement of the activities of the enzymes implied in the metabolism of cholesterol [35]. Li et al. [36] showed that the increase 
in the activity of the Lecithin: Cholesterol Acyltransferase Activity (LCAT) and probably the reduction in that of hydroxy-methyl-glutary-coenzyme A reductase (HMGCoA reductase), both ensuring the homeostasis of cholesterol, could be regarded as persons in charge for the reduction in the cholesterolemy, in the rat subjected to a feeding regime enriched with cholesterol treated with $5 \%$ by the extract by Coriandrum sativum during 75 days [36]. Moreover, Sudhop et al. [37] noted a rise in the activity of the LCAT and an inhibition of HMG-CoA reductase, in the rat made hypercholesterolemic treated with $500 \mathrm{mg} / \mathrm{kg}$ of an extract leaves of Symplocos cochinchinensis, during 28 days [38]. For this reason $C$. occidentalis could have an effect in the increase of the activity of the LCAT and in the reduction of hydroxymethyl-glutary-coenzyme A reductase. it is very difficult to make a difference between efficacy of $C$. occidentalis with the efficacy of other plant extract without knowledge in the content of each plant extract. For the moment we explore the ways that $C$. occidentalis act and tried to explain the effect of the extract.

Our results showed in this model of hypercholesterolemy that several biomarkers of the oxydative stress faded in the rats subjected to the diet rich in cholesterol. The reduced glutathion is the most abundant endogenous antioxydant which interacts with activated oxygenated species, thus preventing the oxidation of the organic substrates (proteins, ADN, fatty acids). It is used as substrate of the glutathion peroxidase. The glutathion is also a trapper of radicals superoxydes and it protects the thiol groups from proteins against oxidation [39]. Our results showed a reduction in glutathione levels in the blood of the hypercholesterolemic rats. The determination of the specific activity of the superoxyde dismutase (SOD), enzyme which catalyses the dismutation of the anion superoxyde $\left(\mathrm{O}_{2}^{-}\right)$out of water and hydrogen peroxide [40]. Faraci and Didion [40] revealed a decrease of the activity of the SOD in blood of the hypercholesterolemic rats. In response to the oxydative stress, the SOD is controlled in two different ways. In the event of moderate oxydative stress one observes a sur-expression of the SOD. If the oxydative stress persists the SOD is destroyed and its expression decreases. Paradoxically, an excessive concentration of the SOD can be dangerous because, in this case, it is the base of a hydrogen peroxide overproduction [41], would be secondary with the increase in the production of $\mathrm{O}_{2}^{-}$[42]., Malondialdehyde (MDA) is used as index of the lipidic peroxidation resulting from the reaction of the active species oxygenated with the membrane fatty acids [43]. In this study, the levels of MDA in blood was significantly increased in hypercholesterolemic rats. In treated group, the aqueous extract of $C$. occidentalis substantially prevented the decrease of GSH and the increase of MDA levels.
The treatment also reduced the activity of the SOD. The polyphenols present in the aqueous extract of $C$. occidentalis [44], could also explain the antioxidant activity of this aqueous extract.

Gupta et al. [45], revealed that; treatment of rats with aqueous extract of Annona squamosa induced a decrease of VLDL-c, LDL, TG levels at the serum and liver and activity of HMG-CoA reductase. Moreover, this extract increased the rate of HDL-c, the activity of the LCAT and the synthesis of the biliary acids at the hepatic level, which involves a rise in the faecal excretion of cholesterol in rat subjected to a feeding regime enriched with cholesterol (2\%) during 75 days. In the current study, it was observed a decrease in the TC, LDL-c, TG levels after treatment with $C$. occidentalis aqueous extract. However, the reduction of those parameters did not reach the normal and could be explained by the short treatment period ( 4 weeks).

The results of this study showed a significant increase in the faecal excretion of cholesterol, in the rats dyslipidemic or hyperlipidemic treated with aqueous extract of C. occidentalis compared with the untreated rats, which suggest an increase in the activity of the $7 \alpha$-hydroxylase, enzyme implicated in the transformation of cholesterol into biliary acids. These results are similar with those obtained with hypercholesterolemic rats, treated with aqueous extract of Globularia alpum, which observed an increase in the synthesis of the biliary acids at the hepatic level and an increase in faecal cholesterol [46].

The aqueous extract of C. occidentalis has an hypocholesterolemia effect and could then act effectively against the transport of cholesterol by the increase in the activity of the LCAT, thus resulting in enrichment of the HDL-c out of cholesterol esters.

\section{Conclusion}

This study provides evidence of antihypercholesterolemia and hypotriglycemia effects of aqueous extract of $C$. occidentalis. It reduces Low Density Lipoprotein cholesterols (LDL-c), triglycerides (TG) and increasing High Density Lipoprotein cholesterols (HDL-c) in rats subjected to a feeding regime enriched with cholesterol. The diuretic activity of this extract justifies its use for the treatment of high blood pressure. However, toxicological studies need to be undertaken to ensure the safety use of this plant extract.

\section{Abbreviations}

C. occidentalis: Cassia occidentalis; CAT: Catalase; $\mathrm{dH}_{2} \mathrm{O}$ : distilled water; GSH: Glutathion; HC: Hypercholesterolemic rats; HDL-c: High density lipoprotein cholesterol; HMG-CoA réductase: Hydroxy-methyl-glutarycoenzyme A réductase; LCAT: Lecithin: Cholesterol Acyltransferase Activity; LDL-c: Low density lipoprotein cholesterol; MDA: Malondialdehyde; NC: Normocholesterolemic rats; ROOH: Hydroperoxide; SOD: Superoxyde dismutase; T: Treatment; TC: Total cholesterol; TG: Triglyceride; VLDL-c: Very low density lipoprotein cholesterol 


\section{Acknowledgments}

We are profoundly grateful to the University of Yaounde I (Cameroon), the Institute of Medical Research and Medicinal Plants Studies (Cameroon), The authors also thank the Laboratory of the Medicinal Plants, Health and Galenic Formulation of the Department of Biological Sciences.

\section{Funding}

The authors declare that they have received no funding for the research reported.

\section{Availability of data and materials}

The datasets supporting the conclusions of this article are presented in this main paper. Plant materials used in this study have been identified at the Cameroon National Herbarium where voucher specimens are deposited.

\section{Authors' contributions}

NF designed the study and were involved in the drafting and correction of the manuscript, analysis and interpretation of data. DT supervised the study improved the mechanism study and corrected the manuscript. BC carried out the plant selection and collection and performed the experiments. TE provided technical assistance in carrying out biochemical assays, contributed some reagents. All the authors read the manuscript, critically revised it for important intellectual content and approved the final version of the manuscript.

\section{Competing interests}

The authors declare that they have no competing interests.

\section{Consent for publication}

Not applicable.

\section{Ethics approval and consent to participate}

Ethical committee of Department of Biological Science of the University of Ngaoundéré (ECDBSUN 15/01/2015/UN/FS/DSB).

\section{Author details}

'Department of Biological Sciences, Faculty of Science, University of Ngaoundéré, P.O. Box 454, Ngaoundéré, Cameroon. ${ }^{2}$ Department of Chemistry, Faculty of Science, University of Ngaoundéré, P.O. Box 454 Ngaoundéré, Cameroon. ${ }^{3}$ Department of Animal Biology and Physiology, Faculty of Science, University of Yaoundé 1, P.O. Box 812, Yaoundé, Cameroon.

\section{Received: 11 May 2016 Accepted: 7 January 2017}

Published online: 25 January 2017

\section{References}

1. Li C, Zhang W, Zhou F, Chen C, Zhou L, Li Y, Liu L, Pei F, Luo H, Hu Z, Cai J, Zeng $C$. Cholesteryl ester transfer protein inhibitors in the treatment of dyslipidemia: a systematic review and meta-analysis. PLoS One. 2013;8:e77049.

2. Madubunyi II, Onoja SO, Asuzu IU. In vitro antioxidant and in vivo antidiabetic potential of the methanolic extract of Ficus glumosa Del (Moraceae) stem bark in alloxan-induced diabetic mice. Comp Clin Pathol. 2012;21:389-94

3. World Health Organization. The tenth revision of the international classification of diseases and related health problems (ICD-10). Geneva: World Health Organization; 1992.

4. Capewell S, Ford E, Croft J, Critchley J, Greenlund K, Labarthe D. Cardiovascular risk factor trends and potential for reducing coronary heart disease mortality in the United States of America. Bull World Health Organ. 2010;88:120-30.

5. Vaessen S, Twisk J, Kastelein J, Kuivenhoven J. Gene Therapy in Disorders of Lipoprotein Metabolism. Curr Gene Ther. 2007;7:35-47.

6. Schwingshackl L, Hoffmann G. Comparison of the long-term effects of highfat v. low-fat diet consumption on cardiometabolic risk factors in subjects with abnormal glucose metabolism: a systematic review and meta-analysis. Br J Nutr. 2014;111:2047-58.

7. Hokanson JE, Austin MA. Plasma triglyceride level is a risk factor for cardiovascular disease independent of high-density lipoprotein cholesterol level: ameta-analysis of population-based prospective studies. J Cardiovasc Risk. 1996;3:213-9.

8. Tsai TH, Tsai PJ, Ho SC. Antioxidant and anti-inflammatory activities of several commonly used spices. J Food Sci. 2005;70:93-7.
9. Hopkins PN, Stephenson S, Wu LL, Riley WA, Xin Y, Hunt SC. Evaluation of coronary risk factors in patients with heterozygous familial hypercholesterolemia. Am J Cardiol. 2001;87(5):547-53.

10. Sans S, Kesteloot H, Kromhout D. The burden of cardiovascular diseases mortality in Europe. Task Force of the European Society of Cardiology on Cardiovascular Mortality and Morbidity Statistics in Europe. Eur Heart J. 1997;18:1231-48.

11. Amano Y, Shimada M, Miura S, Adachi R, Tozawa R. Antidyslipidemic effects of a farnesoid X receptor antagonist in primates. Life Sci. 2014;106:25-31.

12. Leyes P, Martinez E, Larrousse M, Cofan M, Trabal J, Perez-Heras AM, et al. Effects of ezetimibe on cholesterol metabolism in HIV-infected patients with protease inhibitor associated dyslipidemia: a single-arm intervention trial. BMC Infect Dis. 2014;14:497.

13. Braunwald E. Heart disease. Philadelphia: Saunders company; 1997. Vol 3, pp. 1625.

14. Saraf S, Dixit VK, Tripathi SC, Patnaik GK. Antihepatotoxic Activity of Cassia occidentalis. Pharm Biol. 1994;32:178-83.

15. Samy RP, Ignacimuthu S. Antibacterial activity of some folklore medicinal plants used by tribals in Western Ghats of India. J Ethnopharmacol. 2000;69:63-71.

16. Tona L, Cimanga RK, Mesia K, Musuamba CT, De Bruyne T, Apers S, et al. In vitro antiplasmodial activity of extracts and fractions from seven medicinal plants used in the Democratic Republic of Congo. J Ethnopharmacol. 2004:93:27-32.

17. Ntchapda F, Barama J, Kemeta Azambou DR, Seke Etet PF, Dimo T. Diuretic and antioxidant activities of the aqueous extract of leaves of Cassia occidentalis (Linn.) in rats. Asian Pac J Trop Med. 2015;8(9):685-93. http://dx.doi.org/10.1016/j.apjtm.2015.07.030.

18. Trease GE, Evans MC. Textbook of pharmacognosy. Tindall: Bailliere; 1983.

19. Lal J, Gupta PC. Two new anthraquinones from the seeds of Cassia occidentalis. Experientia. 1974;30:850-1.

20. Purushotham KN, Annegowda HV, Sathish NK, Ramesh B, Mansor SM. Evaluation of phenolic content and antioxidant potency in various parts of Cassia auriculata L.: a traditionally valued plant. Pak J Biol Sci. 2014;17:41-8.

21. Alam N, Yoon KN, Lee TS. Antihyperlipidemic activities of Pleurotus ferulae on biochemical and histological function in hypercholesterolemic rats. JRMS. 2011:16(6):776-86.

22. Fatiha O, Rachid S, Nadia EG, Hakima B, Mustapha L, Souliman A, Noreddine G. Hypolipidemic and Anti-Atherogenic Effect of Aqueous Extract of Fennel (Foeniculum Vulgare) Extract in an Experimental Model of Atherosclerosis Induced by Triton WR-1339. Eur J Sci Res. 2011;52(1):91-9.

23. Akabue, Mittal. Hypolipidemic Activities of Dietary Pleurotus ostreatus in Hypercholesterolemic Rats. Microbiology. 1982;39:45-51.

24. Arbonnier M. Arbres arbustes et lianes des zones sèches d'Afrique de I'Ouest. France: CIRAD-MNHN-UICN; 2000. p. 462-63.

25. Friedewald W, Levy R, Fredrickson D. Estimation of concentration of low density lipoprotein cholesterol in plasma without use of the ultracentrifuge. Clin Chem. 1972;18:449-502

26. Bonnefoy M, Abidi H, Jauffret M, Garcia I, Surrace J, Drai J. Hypocholesterolemia in hospitalized elderly: relations with inflammatory and nutritional status. Rev Med Interne. 2002;23:991-8.

27. Fassbender K, Lütjohann D, Dik MG, Bremmer M, König J, Walter S, Liu Y, Letièmbre $\mathrm{M}$, von Bergmann $\mathrm{K}$, Jonker C. Moderately elevated plant sterol levels are associated with reduced cardiovascular risk-the LASA study. Atherosclerosis. 2008;196(1):283-8. doi:10.1016/j.atherosclerosis.2006.10.032.

28. Mohamed AR, El-Hadidy WF, Mannaa HF. Assessment of the prophylactic role of aspirin and/or clopidogrel on experimentally induced acute myocardial infarction in hypercholesterolemic rats. Drugs R D. 2014:14:233-9.

29. Bansal M, Jaswal S. Hypercholesterolemia Induced Oxidative Stress IsReduced in Rats with Diets Enriched with Supplement from Dunaliella salina. Am J Biomed Sci. 2009; 1 (81):196-204.

30. Catapano AL, Farnier M, Foody JM, Toth PP, Tomassini JE, Brudi P, et al. Combination therapy in dyslipidemia: Where are we now? Atherosclerosis. 2014;237:319-35.

31. Davidson MH, Voogt J, Luchoomun J, Decaris J, Killion S, Boban D, et al. Inhibition of intestinal cholesterol absorption with ezetimibe increases components of reverse cholesterol transport in humans. Atherosclerosis. 2013;230:322-9.

32. Terunuma S, Kumata N, Osada K. Ezetimibe impairs uptake of dietary cholesterol oxidation products and reduces alterations in hepatic cholesterol metabolism and antioxidant function in rats. Lipids. 2013:48:587-95. 
33. Mathur R, Sharma A, Dixit VP, Varma M. Hypolipideamic effect of fruit juice of Emblica officinalis in cholesterol-fed rabbits. J Ethnopharmacol. 1996;50:61-8.

34. Halverstadt A, Phares DA, Wilund KR, Goldberg AP, Hagberg JM. Endurance exercise training raises high-density lipoprotein cholesterol and lowers small low-density lipoprotein and very low-density lipoprotein independent of body fat phenotypes in older men and women. Metabolism. 2007;56:444-50.

35. Gami AS, Witt BJ, Howard DE, Erwin PJ, Gami LA, Somers VK, Montori VM. Metabolic syndrome and risk of incident cardiovascular events and death: a systematic review and meta-analysis of longitudinal studies. J Am Coll Cardiol. 2007:49:403-14.

36. Li L, Wang Y, Xu Y, Chen L, Fang Q, Yan X. Atorvastatin inhibits CD68 expression in aortic root through a GRP78-involved pathway. Cardiovasc Drugs Ther. 2014;28:523-32.

37. Sudhop T, Lutjohann D, Kodal A, Igel M, Tribble DL, Shah S, et al. Inhibition of intestinal cholesterol absorption by ezetimibe in humans. Circulation. 2002;106:1943-8

38. Jain GC, Jhalani S, Agarwal S, Jain K. Hypolipidemic and Antiatherosclerotic Effect of Leptadenia pyrotechnica Extract in Cholesterol Fed Rabbits. Asian J Exp Sci. 2007;21(1):115-22.

39. Stein R, Littke R, Stax R, Welte DH. Quantity, provenance, and maturity of organic matter at ODP. Proc Ocean Drilling Program Sci Results Coll Stn. 1989:105:185-208. doi:10.2973/odp.proc.sr.105.154.1989.

40. Faraci FM, Didion SP. Vascular protection: superoxide dismutase isoforms in the vessel wall. Arterioscler Thromb Vasc Biol. 2004;24(8):1367-73. Epub 2004 May 27.

41. Misra, Fridovich. Determination of the level of superoxide dismutase in whole blood. New Haven: Yale University Press; 1972. p. 101-9.

42. Midaoui AEL, de Champlain J. Prevention of hypertension, insulin resistance, and oxidative stress by alpha-lipoic acid. Hypertension. 2002;39(2):303-7.

43. Ntchapda F, Maguirgue K, Adjia H, Seke Etet PF, Dimo T. Hypolipidemic, antioxidant and anti-atherosclerogenic effects of the aqueous extract of Zanthoxylum heitzii stem bark in diet-induced hypercholesterolemic rats. Asian Pac J Trop Med. 2015;359-65. doi: 10.1016/S1995-7645(14)60344-8.

44. Al-Jaff FK. Effect of Coriander Seeds as Diet Ingredient on Blood Parameters of Broiler Chicks Raised under High Ambient Temperature. Int J Poult Sci. 2011;10(2):82-6. 82.

45. Gupta RK, Kesari AN, Diwakar S, Tyagi A, Tandon X, Chandra R, Watal G. In vivo evaluation of anti-oxidant and anti-lipidemic potential Annona squamosa aqueous extract in Type 2 diabetic models. J Ethnopharmacol. 2008;1016(10):3-8

46. Patil R, Prakash K, Maheshwari L. Hypolipidemic Effect of Celastrus paniculatus in Experimentally Induced Hypercholesterolemic Wistar Rats. Indian J Clin Biochem. 2010;25(4):405-10.

\section{Submit your next manuscript to BioMed Central and we will help you at every step:}

- We accept pre-submission inquiries

- Our selector tool helps you to find the most relevant journal

- We provide round the clock customer support

- Convenient online submission

- Thorough peer review

- Inclusion in PubMed and all major indexing services

- Maximum visibility for your research

Submit your manuscript at www.biomedcentral.com/submit

C Biomed Central 